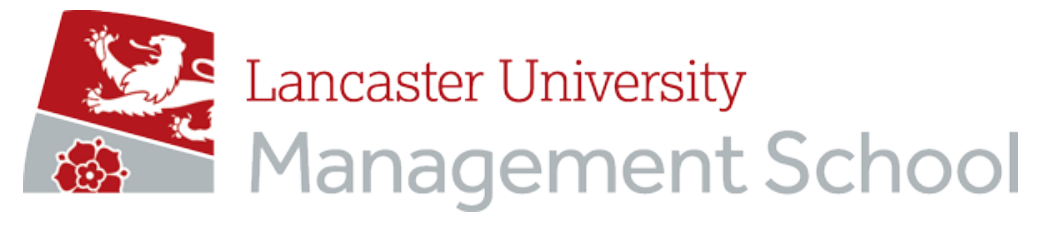

\author{
Economics Working Paper Series
}

2016/010

\title{
Can Services Lead the Indian Economy?
}

\author{
V. N. Balasubramanyam \\ The Department of Economics \\ Lancaster University Management School \\ Lancaster LA1 4YX \\ UK
}

\footnotetext{
(C) Authors

All rights reserved. Short sections of text, not to exceed two paragraphs, may be quoted without explicit permission, provided that full acknowledgement is given.
} 


\title{
Can Services Lead the Indian Economy?
}

\author{
V. N. Balasubramanyam ${ }^{1}$ \\ Department of Economics \\ Lancaster University Management School
}

July 2016

\begin{abstract}
Growth of services in the economy of India is viewed with concern and wonder; concern that services may not provide employment opportunities in an economy with a large number of semi- skilled and unskilled workers, wonder that services account for nearly $60 \$$ of the GNP in a developing economy. This paper outlines the factors that have promoted the growth of services, analyses the structure of the services sector and argues that services can lead the economy contrary to popular opinion.
\end{abstract}

Keywords: Growth, Services, India

JEL: 014

${ }^{1}$ Contact details: V. N. Balasubramanyam, Lancaster University Management School, Lancaster LA1 4YX, United Kingdom. E-mail: v.balasubramanyam@lancaster.ac.uk 
$\underline{\text { Introduction }}$

"Wonder and dismay". This was the comment of a participant at one of the seminars on India's services sector. Wonder at how services could account for $58 \%$ of India's GNP, as high as it is in the developed countries, and dismay that an economy with high levels of unemployment and poverty should rely on services not known for its contribution to low income groups and the poor. This paper argues that whilst these concerns are understandable, they may not be as grave as all that. The factors that have promoted services in the economy, and the nature and structure of the services economy, both suggest as much.

\section{What are Services?}

Much of the debate on services is on the nature of services that differs significantly from manufacturing and agriculture. A well-known definition of services captures some of its features; "A service may be defined as a change in the condition of a person, or of a good belonging to some economic unit, which is brought about as the result of the activity of some other economic unit, with prior agreement of the former person or economic unit" (Hill, 1977). The crux of this definition is that a service changes the condition of a person or good. In other words, it is an input rather than a final good; it changes the condition of the person or the good on which it acts, suggests that the input promotes productivity in more ways than one. It may differentiate the product with which it interacts, it may increase the productive efficiency of the process of production of the product, and it may increase the productive efficiency of those that use product in their chosen occupation. Put briefly, services are inputs that can confer a number of advantages on those that use it, including productive efficiency, product differentiation, and pecuniary and technological externalities on those that are in the ambit of the product that uses the service as an input.

Admittedly, not all services possess these positive characteristics. Some services may be inputs 
whose benefits are static rather than dynamic. They do not enhance productivity of the production process, nor can their output be sold profitably. Adam Smith considered service occupations such as menial servants labour (those providing food and drink to their masters) as unproductive; they cannot be resold or used as inputs into other occupations. He did, however, recognize the worth of services that enhanced productivity. The nature of services and their role in the growth process has undergone significant changes over the last quarter of a century mostly due to revolutionary changes in the realm of transport and communications. Services that were considered to be intangibles and non -storable are storable now, meaning that their role as productivity enhancing complements to goods and other services has increased dramatically. Admittedly, such developments are mostly in the developed countries such as the UK and the USA where services account for more than 70\% Of GNP. These are countries that have transited from agriculture to services along with a productive manufacturing sector. The exception is India, whose economy harbours a varied services sector that accounts for $58 \%$ of the GDP, alongside an agriculture sector none too efficient and productive, and a capital intensive manufacturing sector that contributes $24 \%$ to the national product and employs a bare $20 \%$ of the labour force (Table 1 ).

Table 1

Table showing sectoral shares of GNP and Employment in 2013- 2014

\begin{tabular}{|l|l|l|}
\hline & GNP, 2015 (\%) & Employment, 2015 (\%) \\
\hline Agriculture & 17 & 49 \\
\hline Manufacturing & 26 & 20 \\
\hline Services & 57 & 31 \\
\hline Value & $\$ 2.384$ trillion & 502 million \\
\hline
\end{tabular}

The Nature and Structure of Services in India

The structure of services in India is varied, ranging from highly human capital ones such as 
business services encompassing information technology oriented services, to those that are less intensive in human capital, but labour intensive, such as hotel and restaurant services.

Information and Communications Technology (ICT) oriented services account for $27 \%$ of the value added from services. Those that are not intensive in ICT account for $7.7 \%$ of the value added to GNP by services. The so called non- market services, mostly funded by the Government account for $20 \%$ of which education constitutes $4 \%$ (Table 2 ).

Table 2

Table showing relative contribution of service industries to gross value added and employment.

Panel A: Gross Value Added Share by Service Industries, 1980-2010

\begin{tabular}{lllll}
\hline Description & 1980 & 1990 & 2000 & 2010 \\
\hline Total services & 39.53 & 44.07 & 50.98 & 54.64 \\
Market services & 19.38 & 23.55 & 29.93 & 34.86 \\
ICT intensive services & 14.74 & 17.35 & 22.51 & 27.19 \\
Trade & 10.68 & 11.69 & 13.21 & 15.77 \\
Financial Services & 2.97 & 3.86 & 5.41 & 5.66 \\
Post and Telecommunication & 0.57 & 0.91 & 1.52 & 1.10 \\
Business Services & 0.52 & 0.90 & 2.37 & 4.65 \\
ICT non-intensive services & 4.64 & 6.20 & 7.42 & 7.68 \\
Hotels and Restaurants & 0.80 & 0.96 & 1.32 & 1.48 \\
Transport and Storage & 3.84 & 5.25 & 6.10 & 6.19 \\
Non-market services & 20.15 & 20.52 & 21.05 & 19.78 \\
Public Administration and Defense & 5.01 & 5.89 & 6.52 & 6.10 \\
Education & 2.45 & 3.08 & 4.13 & 3.94 \\
Health and Social Work & 0.93 & 1.22 & 1.60 & 1.53 \\
Other services & 11.76 & 10.34 & 8.80 & 8.22 \\
\hline
\end{tabular}

In total, human capital intensive services including ICT ones and education account for around $31 \%$ of services that contribute to the value added of the economy. Services as a whole 
contribute $30 \%$ of the total employment in the economy, nearly half of which originates in human capital intensive services. The software industry heads the list of human capital intensive services in the economy. It also makes a significant contribution to the exports of the country; exports of software in the year $2014-125$ constituted $81 \%$ of a total output of the industry at $\$ 120$ billion. It is also major provider of employment in the services sector with 2.5 million direct jobs and a hefty 8.9 million indirect jobs. Its contribution as an input to other services such as finance and banking contributes to the human capital intensity of services in general. There is also evidence to show that services are much more efficient than the manufacturing sector (Figure 1). In sum, the structure of services in India is approximately similar to that in the developed countries.

Figure 1

A Table showing Growth Rates of Value Added and Employment, 1980-11 Red donates services, and blue denotes manufacturing

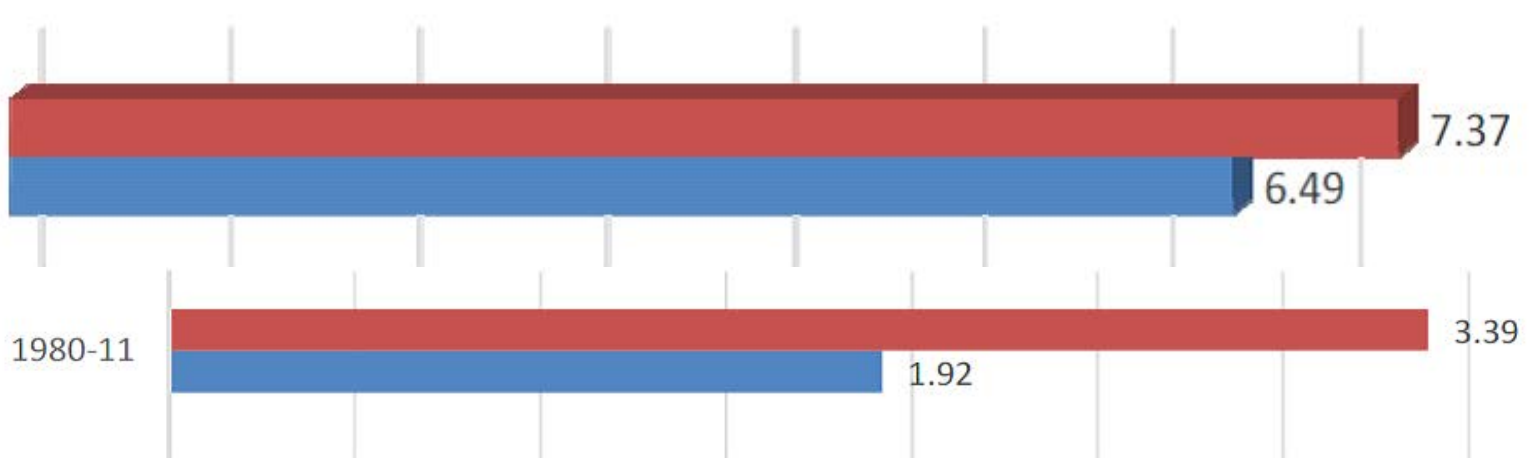

What Explains the Prominence of Services in the Economy of India?

The structure of their economies has progressed from agriculture to services, with manufacturing occupying a significant middle position. In contrast, low income countries services are lower down the scale, with manufacturing contributing to the total output of the economy much more than services. India is an exception. The structure of its economy more nearly resembles that of the high and middle income countries than that of the low income 
countries (Figure 2).

\section{Figure 2}

Chart showing the sectoral structure of world economies, 1995

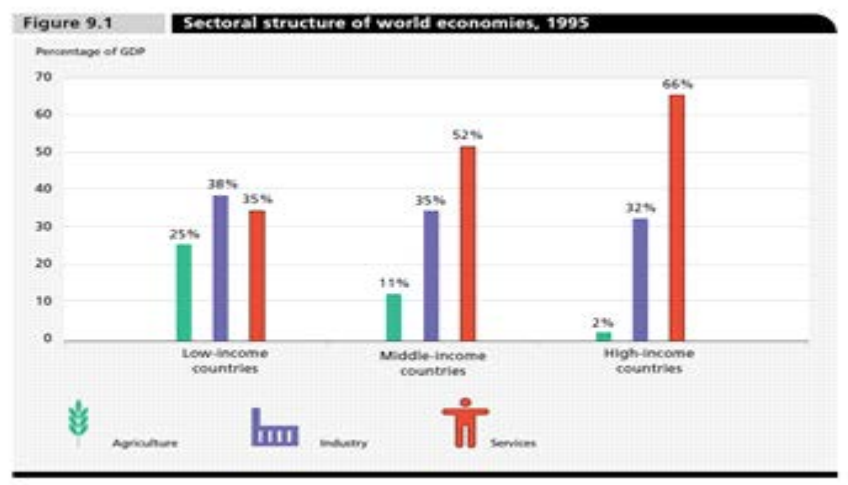

The economic structure of the present day middle income and high income countries can be said to conform to the Kuznets Paradigm on growth and structural change. The central thesis of Kuznets is that economic growth, centered initially on agriculture, results in increasing income inequalities, a growth in demand for manufactured goods, and a growth in the share of manufactures in national income. This then results in the growth of the manufacturing sector and a further increase in income inequalities. Then again, demand for goods and services with relatively high income elasticities increases, and the services sector expands. This spread of demand for goods and services, and employment, lowers income inequalities. This then is the Kuznets paradigm with a relationship between growth, income inequalities, and structural change beginning with agricultural growth, followed by manufactures and then services. These sectoral changes would be accompanied by growth in employment in the manufacturing and service sectors, and a reduction in that of agriculture. Both demand and supply factors are significant in the growth of services over time postulated by Kuznets. Here again, services are primarily an input with a demand from the manufacturing sector, and there is also the demand for consumer services such as tourism with the growth in incomes.

The structural change the economy of India has experienced over the years bears no 
resemblance to the Kuznets paradigm. It has not progressed from agriculture to manufacturing and then on to services, the path of transition envisaged by Kuznets, but has jumped from agriculture to services with a capital intensive manufacturing sector occupying the middle with as low a share as $26 \%$ of the national income. (Table 1 ). Its record on job creation too has turned out to be much below expectations. Labour in agriculture has not moved to manufacturing, though its productivity is low in agriculture; a hefty 50 percent of the labour force of 500 million continues to reside in agriculture. Employment in manufacturing accounts for a low of $26 \%$ of the labour force. Neither the organised sector nor the so called unorganised sector of manufacturing has provided the sort of job opportunities that is expected of them.

There are two broad explanations for the observed structure of the economy of India. First is the economic policy framework; the Nehru-Mahalanobis design implemented during the mid-1950s, a design that lay at the heart of India's planned economic development philosophy and industrialisation programme.

The Nehruvian strategy of industrialisation was ideologically based. As he put it "the problems of poverty and unemployment, of national defence and of economic regeneration in general cannot be solved without industrialisation. As a step towards such industrialisation, a comprehensive scheme of national planning should be formulated. This scheme should provide for the development of heavy key industries, medium scale industries and cottage industries". National regeneration was to be achieved through self-sufficiency in investment goods that would in time produce consumer goods. Hence, the strategy to be driven by the increased production of heavy engineering or capital goods in the short run required a higher allocation of investible resources to the capital goods sector. This strategy, though it may lead to a lower growth rate and low levels of consumption in the short run, would yield a relatively high growth and consumption in the long run. Thus there was an assumption of a low social discount rate in the sense that there would be more tomorrow if less were consumed today.

Promotion of capital goods production requires technology and know-how. This too was to be 
produced indigenously through promotion of science and engineering education. Towards this end, a number of higher education establishments were established that did yield the sort of human capital that was desired. The Indian Institutes of Management and Institutes of technology that were initiated during the decade of the fifties now number 19 and 17 respectively. According to the data published in the Statistical Abstract of India, there were a total of 15,703 degree awarding institutions of higher education in the country at the end of the year 2001-02. These institutions have provided the sort human capital required by the service industries.

But why haven't they served the manufacturing sector too? Why is it that the manufacturing sector and for that matter the agriculture sector lagged behind services and the economy has veered away from the Kuznets path of structural change? The proximate answer to these questions is that capital intensive firms and industries do not require the sort of management and organisation that labour intensive technologies require. As Hirschman says, "labour-intensive technologies by their very nature require much more intensive organisation and supervision than capital-intensive technologies" (Hirschman 1958). In the presence of capital intensive technology, industries supported by policy and state investments the volume of graduates with higher education may have been surplus to requirements. Indeed, the relaxation of immigration regulations and constraints by the USA during the decade of the seventies and eighties appears to have provided a vent for surplus graduates the system had produced. These emigrants or the Indian diaspora were a factor of significance in the growth of the software sector in India. Many of them returned back home to establish software firms and several others headed American owned firms that invested in software in India (Balasubramanyam and Balasubramanyam 2000).

Other reasons for the failure of India to establish labour intensive manufacturing firms such as those in China include labour laws and regulations that the capitalists were none too happy with, the myriad rules and regulations that business entrepreneurs intending to start up manufacturing firms had to cope with, and the reservation of large chunks of manufacturing, 
much of it with an export potential for the small scale industries that for various reasons failed to deliver.

A much more proximate reason for the prominence of services as opposed to manufacturing lies in India's history and sociology. The sort of education policies put in place during the fifties jelled with the aptitude, background of a select class of people that have for long years occupied positions of power and influence. India has always been an elitist society with its hierarchical caste system, dominated by the Brahmins, the ruling class, and the merchant class, commanding power and influence over education, trade and top level administrative jobs.

As Thirthankar Roy observes "the historical pattern of demand for education at all levels was biased towards certain castes and communities because these people had an inherited association with literate services. Groups that had contact with scribal professions, medicine, teaching, and priesthood, in the pre-colonial times, entered education, medicine and public administration in the colonial times. These classes and castes eagerly used the new schools and colleges, while other classes and castes entered schools on a smaller scale, and dropped out more readily. The correlation between family history of literate services, preference for service professions, and thus, preference for education, was especially close in the three port cities Madras, Bombay, and Calcutta". Indeed, India's software industry of the present day reflects the sort of caste oriented education that promoted services in the past. The industry is dominated by members of the middle class, mostly upper castes, especially the Brahmins, that were prominent in civil service jobs in the past" (Taebe, 2003; Upadhya, 2004).

Yet another factor allied to education is the predominance of trade and finance in the India's economy for long. Business culture or managerial expertise and specialism is to be traced to several unique features of the Indian economy. Foremost of these is the inheritance from history. India has had a long history of business entrepreneurship marked by its caste and community orientation. Foremost amongst these groups are the Banias and the Marwaris, primarily merchants and money lenders with a prominent role in financing India's foreign trade 
during the British colonial era. Allied to the caste orientation of the managers was the group or family orientation of firms. These firms produce a diverse range of products, but they all share risks, and draw on a pool of finance and information. They were also traders in their own right. Another group of entrepreneurs were the Parsis, who had no religious affiliation with the Hindu community, and were on a class of their own. As Damodaran (2013) notes, the Parsis had special relationship with the British "being part of neither the Hindu nor Muslim mainstream, nursing no political ambition and exposed to commercial influences because of their proximity to the ports of Bharuch, Surat, and Daman, the Parsis seemed ideal for recruitment as native brokers, agents and shippers".

Again, as Thirthankar Roy writes, "the factors that have promoted the growth of services sector may differ between the various states of India, but two of them may be significant for all of them. First is the significance of trade and finance in India's economic history through the ages but especially so from the British colonial days. The ratio of trade to domestic product increased from a low of 1 to $2 \%$ in 1800 to $20 \%$ by 1914" (Roy, 2011).

The predominance of trade and finance in India's economy over the years has shaped the managerial class as it exists today. Mangers of the day in the private sector are "market managers" rather than "man managers" They are adept at identifying markets for the products their firms produce, locating sources of finance, raising finance, and exploring ways and means of acquiring sources of technology and know-how. They are not, however, adept at organising labour and managing engineering technology. In other words, Indian managers are adept in establishing and promoting service oriented firms rather than manufacturing firms.

Summing up the birth and rapid growth of India's services sector, and the absence of a large labour intensive manufacturing sector are to be traced to India's factor endowments; human capital and services oriented managerial expertise. These developments are grounded in India's history and culture. It should be added that the growth in services are not due to an increase in the price of services relative to that of manufactures that would escalate their size in value 
terms, nor is it due the so called splintering effect when services that were performed along with goods production, as in the case of painting of cars, is outsourced to those specialising in services (Nayyar 2014) It is possible though that the firm specialising in the services that are outsourced may experience growth in productivity (Bhagwati 1984)

Services - The Leading Sector of the Economy?

Whilst there are several explanations for the growth of services in the Indian economy, the issue of concern is "Can services lead the economy and provide the badly needed jobs and incomes for the lower income groups and the ones living in poverty?" Could it lead the economy both as a sector on its own and as a complement to other sectors?

What are the features of a leading sector? How does it lead the other sectors? The Ministry of Finance suggests a set of criterion for a sector to be the engine of growth in the words of the report. The five criteria are (1) High Level of Productivity (2) Domestic Convergence of Productivity of Sectors (3) Expansion (4) Alignment with Comparative Advantage (5) Tradability. India's manufacturing sector complies with the first and second criteria but none of the others. The services sector seems to satisfy the growth and convergence criteria but not the alignment with comparative advantage criteria. One of the notable features of this exercise is its acknowledgement that neither sector satisfies all the criteria, and the policy makers have to decide whether to embrace the Chinese model, or the skills development model.

This is a conclusion that seems obvious, and the Ministry's tilt towards skill intensification seems to be much more appealing than the suggestion of following the Chinese example. For one thing, establishing and organising labour intensive manufacturing is not the comparative advantage of India, as argued in the previous section, and for another it would be almost impossible to snatch international markets from the long established Chinese, and other Asian, exporters of labour intensive goods. The alternative is to promote services as the leading 
sector. Again, in our view, India's comparative advantage lies in the utilisation of the skills it possesses, the ones that have promoted the services sector.

Components of the services sector, such as business services that includes IT related activities, seem to be converging both at home and abroad. The only Ministry of Finance criteria that it does not satisfy is that it is not aligned with the comparative advantage of the country in unskilled labour. As we have argued earlier, this is a very broad reading of the comparative advantage of the country. The country has a comparative advantage in unskilled labour, only on account of the sheer numbers of labourers, but possesses neither the organisation nor the managerial skills to effectively exploit the so called advantage. India's comparative advantage is in services; it relies on the sort of educational and managerial skills the country possesses. The challenge is to utilise the advantage to promote employment and development in the broader sense of the concept of development.

How best to do it? It is essential to keep in mind the obvious fact that most, though not all, services are inputs and not final products. This is especially so in the case of business services that includes finance, insurance and the IT services. It is the effective utilisation of the inputs to produce final goods and services that is the central task facing policy makers. The current PMs call for "Make in India" should be responded to by utilising the service sector inputs to make final goods and not interpreted as adopting the Chinese model. It is encouraging to note that the model we advocate though in its infancy is gathering momentum. In states such as Tamil Nadu, production of components and parts for industries such as motor cars are being moved to rural areas The training of rural labour in these cases is attempted through the utilisation of computer technology. Demonstration of the production process on a computer screen to the unskilled and semi-skilled labour could be quite effective in training them for the task. It is of interest that an empirical analysis of urbanisation of industry across states in India finds that there is a significant movement of plants in formal manufacturing to rural areas, whilst informal sector firms are moving into urban areas (Ejaz Ghani, Arti Grover Goswami, and William R. Kerr). The role of services in both the movement of informal sector firms into urban areas, and 
the vice versa, in the case of formal sector firms could be considerable. The former tend to be labour intensive activities, and the latter are capital intensive. In both cases, IT services could be of significance in facilitating the cross regional movement of plants.

Econometric evidence also shows that the contribution of services to overall growth of the economy is relatively high (Table 4). The contribution of producer services is much higher and significant than that of agriculture and manufacturing to the growth rate.

\section{Table 4}

Table showing the contribution of Agriculture, Manufacturing, and Services to the Growth of State Domestic Product (1980-2007)

\begin{tabular}{|c|c|c|c|c|}
\hline $\begin{array}{l}\text { Growth of } \\
\text { Income }\end{array}$ & Growth of State & omestic Product & & $\begin{array}{l}\text { Growth of } \\
\text { Income from } \\
\text { Service Sector }\end{array}$ \\
\hline Agriculture & $0.331 * * *(7.328)$ & & & \\
\hline Manufacturing & & $0.214 * * *(4.392)$ & & \\
\hline Service & & & $0.664 * * *(16.99)$ & \\
\hline $\begin{array}{l}\text { Producer } \\
\text { Services }\end{array}$ & & & & $0.429 * * *(17.92)$ \\
\hline $\begin{array}{l}\text { Consumer } \\
\text { Services }\end{array}$ & & & & $0.408 * * *(15.46)$ \\
\hline $\mathrm{R}^{2}$ & 0.51 & 0.18 & 0.38 & 0.88 \\
\hline $\mathrm{F}_{\mathrm{STAT}}$ & 384 & 78.8 & 222.25 & 1320.58 \\
\hline Number of obs. & 360 & 360 & 360 & 360 \\
\hline
\end{tabular}

\section{Conclusions}

This brief paper has argued that the structure of the Indian economy with services as the major sector contributing to national income is nothing unexpected or inexplicable. Its origins and 
growth are to be traced to India's economic history, and organisation of the society that has provided the sort of education and managerial know how that facilitates the growth of services. The paper also argues that services can be effectively utilised to promote both growth and development in the economy. This suggestion, though supported by some empirical evidence, requires further research. 


\section{References}

Balasubramanyam VN and Balasubramanyam Ahalya, (2000) The software cluster in Bangalore', in Regions, Globalization and the Knowledge-Based Economy (eds) Dunning JH, Oxford University Press, Oxford.

Bahgwati J N (2004) Splintering and Disembodiment of Services and Developing Nations, World Economy June.

Damodaran H. (2008) “India's New Capitalists", Permanent Black in collaboration with New India Foundation.

Ghani Ejaz, Goswami Grover, Kerr William (2012) Is India's Manufacturing Sector moving out of the Cities, Vox, Centre for Economic Policy research.

Hill TP (1977) "on Goods and Services" Review of Income and Wealth, vol 23 no 4 pp 315-338.

Hirschman Albert (1958) Albert Strategy of Economic Development.

Nayyar, Gaurav (2014) The Services Sector In India's Development, Cambridge University Press.

Roy, T. (2011), "The Economic History of India, 1757-2010", Third Edition, Oxford University Press.

Upadhya C, (2004). "A New Transnational Capitalist Class? Capital Flows, Business Networks, and Entrepreneurs in the Indian Software Industry", Economic and Political Weekly, vol 39(48), pp. 5141-5151. 